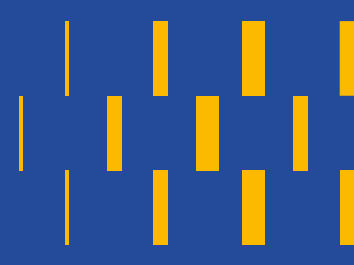

issn $0718-1041(\mathrm{en}$ linea)

\title{
Más allá del mensaje de salvación. Los usos de la conversión religiosa en el Sur Andino peruano
}

\section{Beyond the message of salvation. The uses of religious conversion in the Peruvian Andean South}

Jordi Gascón ${ }^{1}$ (D) https://orcid.org/0000-0002-0947-614X

${ }^{1}$ Universitat de Barcelona, Barcelona, ESPAÑA. Email: jordigascon@ub.edu

\section{Resumen}

El artículo compara dos períodos en la historia de una comunidad quechua (isla de Amantaní, lago Titicaca, Perú). Fueron momentos de conflicto social, en los que la Iglesia Adventista del Séptimo Día jugó un papel significativo. En cada momento, distintos sectores indígenas, con determinados intereses y objetivos políticos y económicos, mostraron mayor predisposición al cambio religioso. Esto demuestra el carácter estratégico de la conversión. Pero el cambio religioso no fue necesariamente una estrategia consciente. Los isleños no advierten la relación entre intereses y opción de fe. La teoría constructivista de Bourdieu permite entender cómo la conversión se adecúa coherentemente a los objetivos de cada grupo social, aunque no sea resultado de la planificación. El estudio se nutre de tres fuentes de carácter cualitativo: la observación participante, entrevistas en profundidad, y archivos públicos y privados.

Palabras clave: adventismo, pueblos indígenas, luchas campesinas, turismo, Andes.

\begin{abstract}
The paper compares two periods in the history of a Quechua community (Amantaní Island, Titicaca Lake, Peru). They were moments of social conflict, in which the Seventh-day Adventist Church played a significant role. At each moment, different indigenous sectors, with different interests, and political and economic objectives, showed greater predisposition to religious change. This demonstrates the strategic nature of the conversion. But religious change was not necessarily a conscious strategy. The islanders do not notice the relationship between interests and the option of faith. Bourdieu's constructivist theory allows us to understand how the conversion coherently fits the objectives of each social group, even if it is not the result of planning. The research is based on three qualitative sources: participant observation, in-depth interviews, and public and private archives.
\end{abstract}

Keywords: adventism, indigenous peoples, peasant struggles, tourism, Andes.

Recibido: 18 septiembre 2020. Aceptado: 2 febrero 2021 


\section{Introducción}

La difusión de confesiones cristianas no católicas entre poblaciones indígenas en América Latina se inició hace más de un siglo. Sin embargo, no despertó el interés de la antropología hasta la década de 1960. En el área centroandina, los primeros trabajos fueron los de Carter (1965). Durante esa y la siguiente década, la mayor parte de la investigación antropológica adoptó una perspectiva crítica, que algún autor ha considerado prejuiciosa (De la Torre, 2014). En unas ocasiones, las nuevas creencias se veían como factores foráneos que agredían la cultura autóctona (p.e., Rodríguez, 1982; Annis, 1987; Crain, 1989). En otras, se consideraban instrumentos de un neocolonialismo cultural y/o político que atentaba contra la soberanía nacional (p.e., Miller, 1970; Martin, 1990; Stoll, 1990). A ello ayudó el escándalo de espionaje de la organización misionera Summer Institute of Linguistics, denunciada por antropólogos latinoamericanos y latinoamericanistas: sus programas de formación de maestros bilingües escondían planes colonizadores en territorios indígenas (Hvalkof y Aaby, 1981). Esta perspectiva afirmaba que la población indígena y las clases populares sufrían una desarticulación de la vida tradicional como resultado de una acelerada modernización subdesarrollada que incrementaba las desigualdades y generaba bolsas de marginalidad, y que este contexto era caldo de cultivo para el éxito de las nuevas confesiones. Se difunde el concepto de 'anomia' para explicar el fenómeno: las nuevas religiones ofrecían alternativas a un individuo que, resultado de esa desarticulación, había perdido referentes culturales y sociales, y veía cómo sus redes familiares y comunitarias se habían roto (Willems, 1967; Lalive d'Epinay, 1968; Stoll, 1990).

Esta mirada estigmatizadora y uniformizadora de la expansión de religiones cristianas no católicas perdió peso cuando la etnografía descubrió que las sociedades indígenas no actuaban como sujetos pacientes. Incluso, sin abandonar la idea de la anomia como motor del cambio de fe, algunos autores detectaron que el neófito jugaba un papel activo en el proceso. Reina y Schwartz (1974) fueron de los primeros en observar que el grado de aceptación del cambio religioso y sus consecuencias variaba de una comunidad a otra, aun cuando la nueva confesión era la misma. Esto evidenciaba que el impacto de este cambio dependía de las características de la sociedad receptora, más que de los principios y prácticas propugnados por la nueva religión. A partir de la década del ochenta, diversos autores observarán que los fieles, muchas veces, adaptan los nuevos preceptos a sus pautas culturales (p.e., Miller, 1975; Bastian, 1983; Mansilla, Muñoz y Orellana, 2014), aunque estas pautas culturales reproduzcan las desiguales relaciones sociales de las haciendas (Martin, 1989).

En los años siguientes esta visión no solo se consolida, sino que va más allá: superando la idea de "adaptación" o "sincretismo", algunos autores empiezan a considerar que la conversión religiosa es una estrategia (Cleary y Steigenga, 2004; Andrade, 2015; Mansilla, Leiva y Piñones, 2020). Ya a principios de la década del setenta, Denton (1971) había observado que muchos creyentes abandonaban la congregación cuando mejoraba su estatus socioeconómico, lo que evidenciaba el carácter estratégico del cambio religioso. Pero será en la década siguiente que esta perspectiva se afiance. En el área andina, Muratorio (1982) es la primera autora que incorpora este planteamiento. En su trabajo en el Chimborazo (Ecuador), entre población campesina quichua, observó que la Unión Misionera Evangélica actuaba como aliada de la ideología dominante al negar la existencia de contradicciones sociales, pero sin lograr alienar a los fieles, que utilizaron los preceptos evangélicos para legitimar sus reivindicaciones políticas, incluso enfrentándose a los elder. Gill (1990) descubre una paradoja en su investigación 
en La Paz (Bolivia): aunque los preceptos pentecostales confirman la jerarquía de género, las mujeres creyentes activan prácticas dentro de la comunidad religiosa que desafían esos principios. Cerca de La Paz, en el altiplano del lago Titicaca, donde se centra la atención del presente artículo, Caram (1997) observó que la conversión religiosa acompañaba los cambios sociales, permitiendo que los indígenas estuvieran en armonía con sus nuevas prácticas.

En las últimas décadas, el apoyo de determinadas confesiones evangélicas y pentecostalistas a gobiernos de derecha radical (Alberto Fujimori en Perú, Efraín Ríos Montt en Guatemala, Álvaro Uribe en Colombia, Jair Bolsonaro en Brasil) ha espoleado la recuperación de un discurso en el que el creyente aparece teledirigido por una élite religiosa y/o está imbuido por un individualismo que le lleva a planteamientos ultraconservadores. Sin embargo, la etnografía sigue revelando el carácter estratégico y plural de la opción religiosa.

En esta línea se circunscribe el presente artículo. El trabajo compara dos períodos en la historia de la isla de Amantaní (departamento de Puno, Perú). Fueron dos contextos de cambios profundos, en los que la Iglesia Adventista del Séptimo Día (IASD) jugó un rol significativo. De población enteramente quechua, Amantaní es la isla más grande y poblada que Perú tiene en el lago Titicaca (Figura 1). A mediados de la década del diez, en pleno conflicto entre los amantaneńos y las haciendas propietarias de la isla, algunos campesinos se adscribieron al adventismo. Solo unos pocos ańos antes, la IASD había empezado su labor misionera en el sur del Perú. El texto confronta los intereses y estrategias de este grupo de isleños adventistas con los de otro sector que empezó a tener un papel política y económicamente preponderante en la década del setenta: aquellos que obtuvieron el control de una nueva actividad económica, el turismo. El carácter estratégico de la conversión religiosa se evidencia porque, aunque la IASD no cambió su doctrina, diferentes grupos de indígenas fueron más proclives al cambio religioso en un momento $\mathrm{u}$ otro.

El artículo cuestiona, también, hasta qué punto el cambio religioso es una estrategia conscientemente planeada. Porque los amantaneños no parecen advertir la relación entre intereses y opción de fe. La teoría constructivista de Bourdieu permite entender cómo el cambio religioso en Amantaní (de católico a adventista, pero también en sentido contrario) se adecúa coherentemente a los objetivos de cada grupo social, sin ser necesariamente una acción planificada o producto de un cálculo razonado.

El artículo es resultado de un trabajo etnográfico realizado a lo largo de cinco años (entre 1990 y 1995), diversas estancias puntuales en años posteriores, y un regreso formal a terreno iniciado en 2018. Las técnicas de investigación utilizadas han sido de carácter cualitativo. Incluyen la observación participativa, las entrevistas en profundidad, la elaboración de historias de vida, y el trabajo en archivos públicos y privados. 


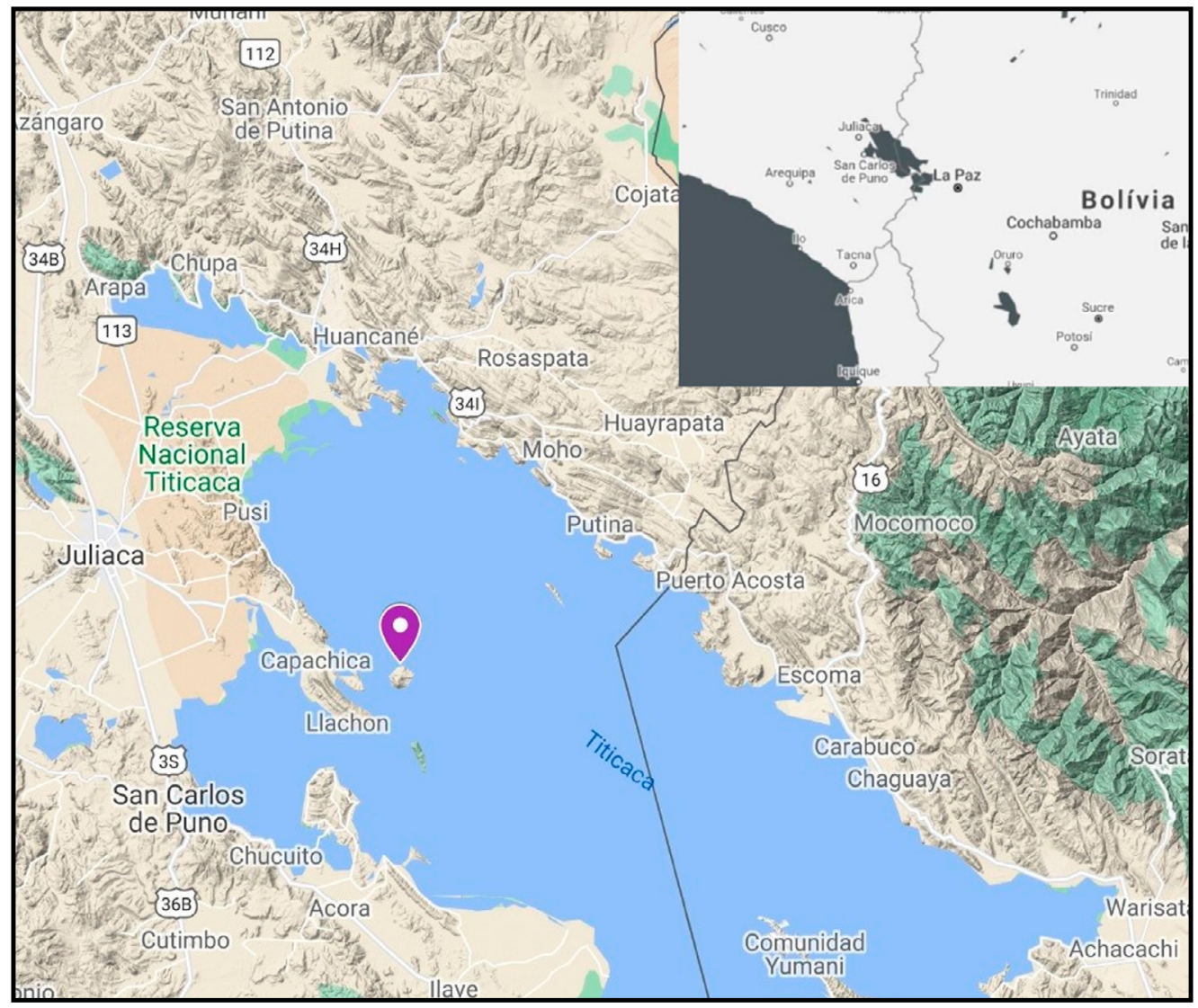

Figura 1. Mapa de localización de la isla de Amantaní. Fuente: Elaboración propia.

\section{Primera escena: cambio religioso y resistencia campesina (décadas 1910 a 1930)}

\section{Amantaní en tiempo de las haciendas}

\section{[...] Y entonces mi abuelo aqui [Isla de Amantaní] vino trayendo el mensaje de salvación. $Y$ unos cuantos se animaron y al pastor [adventista] trajeron, y montaron escuela sabática; 1914, 1915... esos años habian sido (Hilario C.).}

Desde la Colonia, Amantaní fue tierra de haciendas. Las relaciones sociales de producción estaban regidas por la tradición, y se caracterizaban por extraer al colono su trabajo y producción excedente. A cambio, el sistema proveía los mecanismos que posibilitaban la reproducción campesina. Por un lado, permitía que las nuevas familias se quedasen en la hacienda a la que pertenecían sus padres y recibir en herencia las tierras que estos usufructuaban. Por otro, si esas tierras eran insuficientes, el fundo cedía nuevas parcelas.

En cierta manera, vivir en una isla era una metáfora del aislamiento económico que comportaba las relaciones de producción en las que el amantaneño estaba inmerso. Estas relaciones, 
que le obligaban a trabajar las tierras de la hacienda y en otras labores personales para el hacendado (punku), le enajenaban de su fuerza de trabajo excedentaria, de tal manera que no podía acceder al mercado laboral libre. Igualmente, el colono tampoco podía acceder al mercado de bienes, ni como consumidor ni como proveedor, ya que el sistema también le enajenaba su producción excedente. Por un lado, porque el hacendado actuaba como comerciante: las haciendas contaban con una sala-almacén en la que los isleños debían adquirir aquellos productos que requerían. Por otro, porque la hacienda procuraba mantener a sus trabajadores en un estado perenne de endeudamiento. Como comerciante y como prestamista, el hacendado cooptaba ese excedente. Obligaciones ceremoniales como la asunción de cargos en el tradicional sistema de fiestas acababan absorbiendo cualquier sobreproducción campesina.

$\mathrm{Al}$ aislamiento económico del amantaneño hay que añadir el político. Una estructura administrativa débil había convertido al hacendado en un "personaje bisagra" que intermediaba entre el Estado y la población de su hacienda. De esta manera, en Amantaní se confundía el dominio de la hacienda y de sus trabajadores con la gestión del territorio y de sus habitantes (Gascón, 1999, 2017). En los Andes centrales, durante el largo período de estructuración del Estadonación y de establecimiento en el territorio de una burocracia funcionarial, el control político de los sectores sociales subordinados en el mundo rural estuvo a cargo del hacendado. Fue la base del sistema de dominación que en Perú se denominó "gamonalismo" (Mariátegui, 1975; Flores Galindo, 1977), y que Andrés Guerrero (2010) ha teorizado como Administración Privada de Poblaciones. Guerrero utiliza este concepto para explicar cómo el Estado cedió a manos privadas la gestión de sectores sociales subalternos. Esta política fue generalizada en los países latinoamericanos durante el siglo XIX y parte del XX. Aunque formalmente el sistema republicano abolió cualquier distinción jurídica entre la población, las élites rurales asumieron la labor de mantener el control político-legal de la población indígena, considerada no apta para asumir plenamente la ciudadanía. Finalmente, también existía un aislamiento coercitivo: explícitamente, el amantaneño tenía prohibido desplazarse fuera de la isla si no era por encargo del hacendado.

Regresemos a la cita con la que hemos abierto la sección. Si el sistema (ayudado por la insularidad geográfica) mantenía al campesino en un estado de extremo aislamiento o de movilidad controlada, ¿̇ómo y cuándo tuvo la oportunidad, uno de esos isleńos, de establecer contacto con la pequeña misión de la IASD que recién se había establecido en el pueblo de Platería, en la zona aymara del Titicaca? Y no parece que se tratara de un contacto puntual o casual: fue lo suficientemente intenso o constante para que el abuelo de Hilario abandonara el catolicismo y abrazase la nueva religión. El caso sorprende aún más si tenemos en cuenta que la Misión de la IASD estaba formada, en ese tiempo, solo por un matrimonio norteamericano que debía atender un vasto territorio. $\mathrm{Y}$ que ese contacto se dio en un contexto de persecución religiosa tan ilegal (una reforma constitucional garantizaba la tolerancia religiosa desde 1915) como real, impulsada por el Obispado con la aquiescencia de las entidades políticas y la élite regional (Armas Asín, 2002; Teel, 2009).

¿El abuelo de Hilario fue una excepción? Parece que no. Y es que no fue el único amantaneño que contactó con la Misión de la IASD.

Dicen que mi abuelo varios años enfermó con ataque. Donde los curanderos fue, a los que tiraban coca. En Puno escuchó que en Platería habia un curandero. Allá fue con su esposa y con mi papá. Seguro mi papá tendría catorce o quince años. Allá fue. Allá 
estaba el pastor Fernando Stahl, en Platería. El pastor le examinó. Era médico. Mi abuelo se curó y a poco se volvió sano. Y allá se bautizó. Mi papá se quedó en escuela particular, en Plateria (Manuel M.).

Más que una excepción, los abuelos de Manuel e Hilario fueron un síntoma. Y es que, como veremos, la conversión religiosa se enmarca en la crisis del sistema de hacienda.

\section{La crisis del modelo}

[...] has debido cumplir sin disculpa alguna todas sus ordenes que te dejo, y si no has cumplido te hare responsable de todo y usare ya medios que tengo de hacerte doler arto pues no soporto robos ni lisuras por que ire y entonces te hare sentir el peso de la justicia. ${ }^{1}$

A partir de la segunda mitad del siglo XIX, Amantaní se caracterizó por ser un territorio políticamente efervescente. Hubo tres sublevaciones entre 1867 y la década del diez. La primera se enmarca en la llamada Guerra de Castas. La Guerra de Castas hace referencia a los numerosos levantamientos que se dieron en la década de 1860 en el departamento de Puno. Los colonos de Amantaní, "donde un doctor había promovido los tumultos" (Burga y Flores Galindo, 1984, p. 29), invadieron las haciendas. A principios de la década de 1880 y a mediados de la de 1910, los amantaneños se levantaron de nuevo contra los propietarios de los fundos. La causa inmediata de la primera habría sido los excesivos abusos que padecían los campesinos por parte de los hacendados. La segunda, la oposición campesina a la compra ilícita de tierras por parte de un magistrado de la Corte Superior de Justicia de Puno. Al menos en una de estas dos últimas rebeliones un hacendado fue ajusticiado, y en ambas la respuesta criolla fue cruenta, con el bombardeo de la isla por parte de la Marina de Guerra y la intervención a sangre y fuego del Ejército (González Prada, 1981).

Las causas inmediatas de los levantamientos siempre fueron abusos puntuales cometidos por los propietarios. Pero detrás se escondía un factor desestabilizador de raíz más profunda: la crisis de la economía moral en que se basaba el contrato entre hacendado y colono. Una crisis impulsada por la presión demográfica relativa sobre los medios de producción. La hacienda requiere un determinado equilibrio entre población trabajadora y recursos disponibles. Si este equilibrio se rompe, los mecanismos de control pueden fallar y el sistema se colapsa. Como afirma Meillassoux (1979, p. 12), "in serfdom, at a given low rate of agricultural productivity, the demographic growth of the productive domestic cell must be limited if a surplus product is to be extracted from it". En este contexto, los amantaneños simplemente reclamaban el mantenimiento de los principios que regían tradicionalmente su relación con la hacienda: el contrato obligaba al hacendado a ceder en usufructo a sus colonos los medios de producción necesarios para su reproducción (Gascón, 2000).

El sistema de hacienda en Amantaní, pues, se hallaba frente a un dilema: la propiedad mantenía un número de colonos superior al óptimo, pero las relaciones de producción no le permitían deshacerse de sus trabajadores excedentarios. Las haciendas optaron por una solución salomónica: no expulsar a nadie y permitir a sus colonos la transmisión por herencia de las

1 Carta enviada por el propietario de la hacienda Cuentas a su capataz. Fechada el 1 de abril de 1947. Archivo personal de Juan Juli. En esta, y en citas posteriores, se mantienen los errores gramaticales de los textos originales. 
parcelas que usufructuaban, pero no ceder (o ceder raramente) nuevas tierras a las nuevas generaciones. El crecimiento demográfico y la herencia divisa provocó que el acceso de los hijos a los recursos agrarios de subsistencia fuese inferior que el de los padres. Las condiciones de vida de los amantaneños se endurecieron generación tras generación.

Y si un elemento tan esencial en el contrato consuetudinario que regía la hacienda estaba colapsando, también lo hacía el papel del hacendado como administrador de poblaciones. Las rebeliones antes citadas solo fueron la expresión más visible de la conflictividad que vivía la isla. A medida que ese contrato no otorgaba los beneficios esperados, aumentaron los robos a los almacenes de las haciendas, la desobediencia a las órdenes del propietario, y el enfrentamiento entre colonos allegados al fundo y otros rebeldes. Ante esta situación, los hacendados, que en su práctica totalidad eran absentistas, enviaban cartas a los colonos que actuaban de capataces cargadas de amenazas y órdenes de castigo, como la del fragmento que hemos citado anteriormente. Pero la reiteración de este tipo de amenazas indica que no surtían efecto.

\section{La estrategia campesina}

\section{Reclamando derechos civiles. Contra el pongaje}

Mediante la presente orden, todos los habitantes de esta Isla, se supertarán á las disposiciones de la Gobernación, cumpliendo estrictamente las órdenes impartidas mediante el Teniente gobernador i los Mandones, procurando todos de que no se ocasionen dańos, ni se cometa ningún abuso; de todo lo que dará cuenta estricta el citado Teniente Gobernador, bajo responsabilidad. ${ }^{2}$

Hacendados poco eficientes como administradores de poblaciones, por un lado. Un Estadonación que iba alargando sus tentáculos en el territorio, por otro. Lentamente, la burocracia funcionarial empezó a tomar las riendas en la gestión política de Amantaní. La anterior cita, fragmento de un oficio redactado en 1927 por el gobernador de Capachica para su lectura pública, ejemplifica este proceso. No será la única carta que este cargo político enviará reclamando obediencia a sus órdenes y su vigilancia por parte de los cargos indígenas tradicionales (varayoc) y del teniente-gobernador (cargo que ostentaba el único hacendado que vivía regularmente en Amantaní). Y como en el caso de las cartas amenazantes de los hacendados, con un éxito relativo. Aún en 1952, el alcalde del distrito de Capachica se quejaba del incivilizado comportamiento del indígena isleńo y de la necesidad de incrementar las medidas represivas (Discurso del alcalde de Capachica, 23 de agosto de 1952).

¿A qué se debía la desobediencia de los amantaneños? Robos en el almacén de la hacienda, de la cosecha en el campo o incluso de ganado se explican por la necesidad de compensar los ingresos domésticos por la escasez de tierras y la imposibilidad de buscar otras fuentes de ingresos fuera de la isla. Pero buena parte de los actos de desobediencia no se debían a razones tan materiales. En una larga carta fechada en 1917 y dirigida al Prefecto del Departamento de Puno, tres amantaneños explicaban cómo uno de los firmantes, comisionado por los "indígenas de la isla", había viajado a Lima para reclamar al gobierno "las garantías i apoyo a que tenemos derecho". Estas reclamaciones se referían a que los isleńos todavía estaban obligados a realizar "pongaje, mitanes i demas servicios gratuitos que se acostumbraban anteriormente", ${ }^{3}$ servicios

2 Oficio fechado el 23 de marzo de 1927. Archivo Departamental de Puno.

3 Carta fechada el 11 de junio de 1917. Archivo personal de Ambrosio Mamani. 
que habían sido derogados por ley hacía una década. ${ }^{4}$ Los campesinos comisionados explicaban que habían obtenido del gobierno un decreto "mandando que informe esta Prefectura de Puno, sin perjuicio de otorgarnos las garantías i apoyo a que tenemos derecho". Pero afirmaban que los hacendados no tenían la intención de prescindir de estos servicios. Y que incluso reclamaban la presencia de gendarmes de Puno para reprimir a los colonos que se oponían.

La carta (y el conflicto que narra) hace referencia a la aplicación de un servicio laboral, y por tanto se encuadra en el ámbito económico de las relaciones entre las partes. Pero refleja algunos elementos que indican que el papel político del terrateniente estaba ya en crisis: a) los colonos (al menos, algunos de ellos) reclaman sus derechos civiles como ciudadanos; b) dirigen estas reclamaciones directamente a las instituciones públicas (incluso enviando comisiones a Lima); y c) los hacendados también tienen que dirigirse a esas instituciones públicas (la Gendarmería) para imponer su voluntad. Eso no quiere decir que el hacendado no tuviera ya capacidad para imponer su autoridad, pero ahora dependía del papel coercitivo del Estado.

\section{Reclamando derechos políticos. El cambio religioso}

En respuesta á su estimable oficio \# 1512 de 6 del presente, y cumpliendo el tenor, procedí á mandar comisionados á la Isla de Amantaní, con el objeto de capturar al misionero evangelista, quien no ha sido habido en dicha Isla; y en virtud de ello he impartido órdenes para la captura de dicho individuo asi como se encuentre en la Isla mencionada. ${ }^{5}$

Con este fragmento de un oficio de 1918 enviado por el gobernador de Capachica al subprefecto de Puno retomamos el tema del cambio religioso. Sin duda el "misionero evangelista" era, en realidad, adventista. Extirpar la nueva religión no solo era interés de los cargos políticos departamentales. Las violentas persecuciones de los conversos por parte de los hacendados han quedado apuntaladas en la memoria histórica de los amantaneños.

¿A qué se debía el interés de los colonos, o al menos de sectores destacables de ellos, por la IASD? ¿Y el de los hacendados, Iglesia católica y cargos públicos en erradicarla? Creemos que el tema se explica fundamentalmente por dos razones. La primera es que el trabajo misional de la IASD se basaba en la conversión civilizatoria del indígena. Eso pasaba por cambiar algunos de sus hábitos y, especialmente, promover la escolarización (Ströbele-Gregor, 1989; Teel, 1989).

El otro elemento a considerar es que Perú había restringido progresivamente el censo electoral desde la Independencia (Mücke, 2004). Este proceso alcanzó su cénit durante el período Civilista (1899-1919), cuando el derecho a voto se estableció solo para los varones letrados. En la práctica, esto limitó formalmente la ciudadanía plena por razones étnicas, pues la población indígena era, salvo excepciones, analfabeta (Portocarrero, 1995). Diferentes autores coinciden en que el voto rural e indígena siempre había estado mediatizado por los grupos de poder local, por lo que la restricción del censo convirtió en ley una ficción de democracia (Basadre, 1980; Peloso, 1996). Pero también es verdad que la institucionalización de esta situación explica que, aún en una fecha tan tardía como 1931, en el Departamento de Puno solo el 2,21\% de la población tuviera derecho a voto (López Jiménez, 2010).

4 La demostración de que el respeto de la ley fue muy imperfecto es que la abolición tuvo que ser decretada de nuevo en 1931 por el gobierno de Sánchez Cerro, y en 1947 por el gobierno de Bustamante.

5 Oficio fechado el 16 de septiembre de 1918. Archivo Departamental de Puno. 
La clave del conflicto religioso estaba, así, en la alfabetización. El acercamiento de los amantaneños a la nueva religión no se debía tanto a sus preceptos doctrinales. De hecho, debía ser complicado convencer a los creyentes de la prohibición, propugnada por el adventismo, de prácticas tan arraigadas como la ingestión de alcohol y de carne de animales considerados impuros (cerdo, cuy), del pijcho (mascado de coca) o de la participación en las fiestas. El interés se debía a que solo la IASD ofrecía servicio educativo a la población indígena puneña. Y que, entre otras cosas, la alfabetización permitía la plena ciudadanía (Gascón, 2015). La persecución del adventismo y especialmente de su "subproducto", la escuela, se mantuvo en Amantaní hasta bien entrada la década del veinte.

\section{El fin del sistema de haciendas en Amantaní}

Acá había una escuela, en mi casa. Por eso los mistis maltrataban a mi papá. “Por qué ese indio puede hablar castellano?, ¿por qué puede leer?, aqui solo podemos hablar castellano los mistis" (Ambrosio M.).

El acoso a la nueva religión tuvo éxito durante un tiempo. A finales de la década del veinte no había adventistas en la isla. Pero en la década siguiente volvieron a reaparecer, y esta vez sí consiguieron establecer y consolidar una escuela.

Cambio religioso > escolarización y alfabetización > derecho al voto. Este fue el tortuoso camino que tomaron los amantaneńos para alcanzar la plena ciudadanía, al menos en lo referente a su derecho a participar en la elección de cargos públicos. Y colateralmente, socavar el papel del hacendado como administrador de poblaciones.

La crisis del contrato consuetudinario que regía las relaciones de producción en la hacienda no explica, por sí sola, la crisis de la Administración Privada de Poblaciones. Otros factores también la socavaron. Por un lado, a medida que se consolidó el Estado-nación, el Estado republicano asumió su rol burocrático en todo el territorio. Por otro, es dudoso que unos hacendados absentistas estuvieran interesados en mantener esas funciones. No obstante, al menos en el caso amantaneño, esa crisis de la economía moral fue un factor que minó sus cimientos.

A partir de la década del cuarenta, los amantaneños vieron que su reproducción pasaba por incrementar la frontera agraria campesina en detrimento de las tierras de la hacienda. Ahora ya como sujetos políticos, presionaron sobre los hacendados para que vendieran sus propiedades. Este proceso terminó en 1964, cuando consiguieron comprar el último y más extenso fundo, el Isla Cuentas. De esta manera, la pérdida de las funciones político-administrativas de la hacienda fue la primera fase de su desaparición.

\section{Segunda escena: cambio religioso y turismo (décadas 1970 a 1990)}

\section{Turismo comunitario en Amantaní}

Paralelamente a la compra de las haciendas, y el consiguiente incremento de la frontera agraria campesina, se dio un fuerte crecimiento demográfico en la isla. Entre 1950 y 1993, la población pasó de 1700 a 3888 habitantes. Esto y el sistema de herencia divisa provocó una 
disminución de los recursos agrarios por familia. El efecto del incremento del tamaño de las explotaciones campesinas con la compra de las haciendas solo duró una o dos generaciones. Se acentuó el minifundio. Este contexto impulsó la emigración temporal. Este tipo de emigración ya se había iniciado en el período de compraventa de las haciendas, cuando muchos amantaneños salieron a conseguir dinero para adquirir tierras.

Otra estrategia para combatir la reducción per cápita de los ingresos agrarios fue la diversificación económica: el transporte de mercancías y personas, y el establecimiento de "tiendas de abarrotes" (ultramarinos) fueron algunas de las nuevas actividades. En este esfuerzo por diversificar la economía, y aprovechando el atractivo del lago Titicaca, en la década del setenta los amantaneños iniciaron la actividad turística. Considerando que este nuevo recurso tenía que favorecer a toda la comunidad, se estableció un sistema de turnos para distribuir a los visitantes entre las familias que deseaban alojar visitantes. Estas familias tuvieron que pagar un impuesto y acondicionar una de sus habitaciones a los requisitos exigidos por el Estado. Estas condiciones hicieron que la mayoría de los isleños desistiesen y se conformasen con otros beneficios que se gestionaron de manera comunitaria, como la venta de artesanías. Pero un número importante de familias hizo la inversión y se incluyeron en el sistema de turnos.

La población amantaneña tenía grandes expectativas en el turismo, pero pronto descubrió sus limitaciones. Por un lado, a una insuficiente promoción de la oferta se sumaba la exitosa competencia de la vecina isla de Taquile, más accesible al turista por su mayor proximidad a la ciudad de Puno. Por otro, el conflicto armado entre el Estado y las guerrillas hundió el sector turístico peruano desde la década del ochenta hasta mediados de la siguiente. Los pocos viajeros que llegaban a Amantaní, sumado a su elevado número de habitantes, hizo fracasar el sistema de turnos. En este contexto, un determinado sector se hizo con el monopolio de ese escaso turismo: los lancheros. No les fue difícil, ya que controlaban el transporte de personas. Gracias al control de los "medios de producción" que permitían trasladar a los turistas, 57 familias monopolizaron los ingresos por el alojamiento turístico a mediados de la década del ochenta. El resto de la población quedó excluido (Pérez y Gascón, 1997; Gascón, 2005b, 2011).

El sector lanchero había surgido en el proceso de diversificación económica antes indicado. Algunos isleños optaron por compatibilizar el trabajo agrícola con el transporte de personas y mercancías. Para ello, organizaron cooperativas destinadas a reunir el capital necesario para la adquisición de la embarcación. Solo las familias con cierto nivel de capitalización pudieron optar a esa actividad, ya que requería una inversión importante. Por el origen del capital invertido, estas unidades domésticas se pueden clasificar en dos tipos. Un primer grupo estaba formado por individuos descendientes de capataces de las haciendas. Durante el período de haciendas, los capataces usufructuaban los lotes de tierras más grandes. Esto les permitió capitalizarse con mayor facilidad y aportar más dinero cuando los campesinos adquirieron las haciendas. De esta manera, pudieron adquirir una mayor cantidad de tierras que sus vecinos. El otro grupo estaba formado por campesinos que tuvieron éxito en la emigración. De los 87 patrones que había en 1995, 62 formaban parte de este segundo grupo.

Si bien el turismo era insuficiente para generar beneficios a toda la comunidad, su monopolio permitió a los lancheros una ostensible mejora de su nivel económico. Un cálculo estimativo indica que los ingresos totales por alojamiento turístico fueron aproximadamente 22500 dólares en 1995. Un reparto equitativo entre toda la población de la isla habría supuesto 5,6 dólares anuales per cápita. Sin embargo, su distribución se dio solo entre lancheros. Teniendo en cuenta que en 1995 operaban quince embarcaciones en Amantaní, los ingresos por lancha 
fueron de 1500 dólares. El número de propietarios de embarcación total era 87, lo que significa unos ingresos medios por lanchero de 258 dólares anuales. ${ }^{6}$ A esta cantidad habría que sumar las ganancias por el transporte del turista (Gascón, 2005b).

Un sistema de turnos aseguraba que todas las embarcaciones realizaran el mismo número de viajes. Por tanto, los ingresos que recibía cada embarcación por el alojamiento de turistas eran similares. Sin embargo, no lo era la distribución de los ingresos dentro de cada lancha. Por una parte, porque el número de lancheros no era el mismo en cada embarcación. Y por otra, porque los patrones de una lancha no tenían las mismas prerrogativas: a aquellos patrones que habían invertido más capital en la adquisición de la lancha les tocaba un mayor número de pernoctaciones de turistas. A modo de ejemplo, la embarcación Virgen de la Candelaria era de un solo propietario. En la Solimar, los propietarios eran cuatro, que se repartían los ingresos equitativamente. En la Independencia, eran diez, y se distribuían los beneficios porcentualmente a su aportación en la compra de la lancha, que había sido muy desigual. Las diferencias eran, por tanto, considerables.

La frustración de las esperanzas depositadas en la nueva actividad por parte de la mayoría de los isleńos hizo que, desde la década del ochenta, el "reparto de turistas" se convirtiera en la principal causa de conflicto entre la comunidad. "Lancheros rateros" era un lema que se repetía en grafitis repartidos por toda Amantaní. Además, la desigual distribución de sus beneficios se convirtió en el eje alrededor del cual se vertebraron las diferencias socioeconómicas entre las familias amantaneńas. Otras actividades, como la agropecuaria o la emigración temporal, jugaban un papel económico más importante en la economía global de la isla. Pero salvo excepciones, la distribución de los ingresos que generaban era relativamente homogénea. En este contexto, que un pequeño grupo de personas obtuviera un plus de ingresos le consolidó como el sector social económicamente preponderante. Y le permitió controlar el cargo político más importante de la isla: la Gobernación.

\section{El control del poder político}

Entre 1975, cuando los isleños decidieron impulsar el turismo, y 1995, casi todos los gobernadores fueron propietarios de lanchas (Tabla 1). Dos factores permitieron este control. El primero es que se trataba de un cargo costoso. Solo a principios de la década del noventa empezó a recibir un presupuesto del Estado. Sin embargo, el cargo conllevaba elevados gastos ceremoniales. Y mucha dedicación: el gobernador no podía practicar la emigración estacional mientras ocupaba el cargo, e incluso debía descargar sobre su grupo doméstico, familiares y compadres parte de su trabajo. Los costos del cargo de gobernador eran tan elevados que, en ocasiones, él y su familia debían ahorrar durante años, activar las relaciones de reciprocidad con sus allegados, emigrar temporalmente o incluso vender parte de su ganado. Por todo esto, solo isleños con la suficiente capacidad de capitalización podían ser gobernadores. Y como hemos visto, a partir de los ańos ochenta, ser lanchero era el elemento identificativo del grupo económicamente preponderante.

El segundo factor que permitió el monopolio lanchero de la Gobernación fue el sistema de elección. El gobernador saliente elegía a tres candidatos para sustituirle. La terna se presentaba a la Asamblea Comunal, que escogía al nuevo gobernador entre los aspirantes. La estrategia del

6 Estimaciones establecidas a partir de datos obtenidos en el trabajo de campo y el cotejo del Libro de Actas del Sargento de Playa de Amantaní, el Libro de Actas de la Empresa de Transporte Turística Lacustre (empresa que reúne a todas las lanchas) y los libros de actas de diferentes cooperativas lancheras. 
gobernador saliente era preparar una terna adecuada a los intereses del grupo: los candidatos siempre eran lancheros, allegados o personas no interesadas en los conflictos generados por la gestión del turismo. Así, entre 1975 y 1995, solamente en dos ocasiones fueron elegidos no-lancheros, pero con la aquiescencia de estos: eran individuos que no tenían interés en participar en el conflicto por el recurso turismo porque se dedicaban con éxito a otras actividades (Tabla 1).

Tabla 1. Gobernadores de Amantaní y características económicas y religiosas.

\begin{tabular}{|c|c|c|c|}
\hline Nombre & Ańo de gobierno & Religión (*) & Actividades económicas $\left.{ }^{(* *}\right)$ \\
\hline Julián S. & 1968 & Adventista & Poseía mucho terreno \\
\hline Mariano Q.Y. & 1969 & Católico & Ganadero \\
\hline Aurelio Y. & 1970 & Católico & Lanchero. Propietario de tienda \\
\hline Manuel M. & 1971 & Adventista & Artesano peletero \\
\hline Julián J. & 1972 & Adventista & Propietario de tienda \\
\hline Mariano Q.P. & 1973 & Católico & Actividades diversificadas \\
\hline Félix J. & 1974 & Adventista & Propietario de tienda \\
\hline Ambrosio M. & 1975 & Católico & Lanchero \\
\hline Francisco Q. & 1976 & Católico & Lanchero. Propietario de tienda \\
\hline Esteban J. & 1977 & Católico & Lanchero \\
\hline Anastasio P. & 1978 & Católico & Lanchero \\
\hline Eleuterio Q. & 1979 & Católico & Lanchero \\
\hline Mariano P. & $1980-1981$ & Católico & Lanchero \\
\hline Toribio J. & $1982-1983$ & Católico & Lanchero \\
\hline Valentín Q. & 1984 & Católico & Lanchero \\
\hline Albino Y. & 1985 & Católico & Lanchero \\
\hline Gabriel C. & 1986 & Adventista & Lanchero \\
\hline Ignacio $\mathrm{C}$. & 1987 & Adventista & Lanchero. Propietario de tienda \\
\hline Mariano B. & 1988 & Adventista & Lanchero \\
\hline Pedro J. & 1989 & Adventista & Exportación de artesanías \\
\hline Moisés Y. & 1990 & Adventista & Lanchero \\
\hline Alfredo V.C. & $1991-1992$ & Adventista & Lanchero \\
\hline Gonzalo P. & 1993 & Adventista & Lanchero \\
\hline Cresenciano Y. & 1994-1995 & Adventista & Poseía mucho terreno \\
\hline
\end{tabular}

*Religión en el momento de ocupar el cargo de gobernador **Característica económica que le permite tener un nivel económico alto Fuentes: Libro de Actas de la Gobernación de Amantaní y entrevistas. 
Dos razones explican el interés por parte de los propietarios de las embarcaciones en asumir un cargo tan demandante en esfuerzo y recursos. Una era contrarrestar la oposición de ciertos sectores de la comunidad a su monopolio sobre el turismo: desde la Gobernación, dificultaban cualquier intento de reglamentar un reparto equitativo de los turistas. El éxito de los lancheros en su oposición a los intentos de establecer la figura del repartidor de turistas se debió tanto a su control sobre el transporte de turistas como al respaldo de esta institución política.

La otra era utilizar en su provecho los recursos controlados por la Gobernación, incluida la fuerza de trabajo isleña en forma de labores comunales. Un repaso de los libros de actas de la Gobernación descubre que un importante porcentaje de los proyectos ejecutados por esta institución entre 1975 y 1996 coincidía con los intereses de los patrones de lanchas: construcción, reconstrucción y ampliación de muelles y atracaderos, y acciones de promoción turística.

Las actas de la Gobernación reflejan que era extraño el año en que no se realizaban obras de consideración destinadas a mejorar o arreglar las infraestructuras portuarias. En la década del setenta prácticamente todos los núcleos de población de la isla tenían un espigón o atracadero. Pero durante las décadas del ochenta y noventa casi todas se ampliaron y se convirtieron en muelles capaces de resguardar dos o más lanchas. Obviamente, eran los patrones de lancha los más beneficiados en la construcción y mantenimiento de los muelles, ya que les eran imprescindibles para salvaguardar sus embarcaciones de los embates del oleaje y el viento. En cambio, su utilidad para el resto de la comunidad era incierta, ya que el crecimiento de estas infraestructuras fue resultado del aumento del número de lanchas y no de sus necesidades de transporte. Las quince lanchas que funcionaban a mediados de los años noventa eran excesivas para cubrir su necesidad de transporte. Considerando solo el transporte de isleńos y mercancías, no era posible el mantenimiento de tantas embarcaciones. La formación de nuevas sociedades lancheras no era resultado de una demanda endógena, sino del deseo de participar en los beneficios del turismo.

Por otra parte, a medida que los lancheros consolidaron su control sobre la Gobernación, esta institución fue reduciendo su participación y contribución a las diferentes fiestas que jalonaban el calendario socio-religioso de Amantaní.

\section{Cambio religioso}

Si bien los lancheros estaban dispuestos a sacrificar parte de sus beneficios para mantener el control de la Gobernación, no lo estaban para invertir recursos en los mecanismos tradicionales de distribución de excedentes: el sistema de fiestas.

En Amantaní, la mayor parte de las fiestas públicas se mantenían gracias a los cargos de alferado y mayorazgo. El primero costeaba los gastos de tipo religioso, como los honorarios del sacerdote y las velas. El segundo, los propiamente festivos como los bailes y la música. El elevado costo que comportaban las fiestas, y que estos cargos habían de soportar, era su característica más sobresaliente. Los cargos festivos eran ostentados en ocasiones motu proprio. En otras, como resultado de la presión social y de los requerimientos de los cargos políticos, y generalmente por una combinación de ambos factores. El sistema de fiestas era, pues, coactivo y voluntario a la vez: los más acomodados se veían motivados a asumir los cargos festivos porque la comunidad esperaba eso de ellos, porque sabían que su aceptación les daría prestigio en la comunidad, y porque en caso de no aceptarlos podían ser castigados con la pérdida de poder 
social y político. Cabe destacar que, en sociedades indígenas tradicionales, el prestigio es un valor práctico y no simplemente simbólico (Carlsen, 1999).

Las tesis clásicas funcionalistas afirman que uno de los roles que juega la fiesta en América Latina es controlar la diferenciación social: el patrocinio de las fiestas obliga a los individuos con mayor capacidad económica a desprenderse de sus excedentes. De esta manera se consolida la solidaridad del grupo (Marzal, 1971; Foster, 1972). Pero si bien es indiscutible el papel que la fiesta tiene como mecanismo redistribuidor del excedente campesino, ello no comporta una disminución de la diferenciación social. El empobrecimiento que un individuo puede sufrir al gastar sus excedentes es ficticio, porque sigue manteniendo la propiedad de los medios de producción que generan esos excedentes y que le otorgan su estatus (Gascón, 2005a).

Pero a medida que Amantaní se fue incorporando a la economía global, estos mecanismos redistributivos empezaron a entrar en crisis. Como ya hemos visto, el proceso de compraventa de las haciendas obligó a los amantaneños a salir de la isla para capitalizarse. Este proceso les incorporó al mercado capitalista de bienes y de trabajo. Esta relación con el mercado capitalista se intensificó en los siguientes años, a la par que crecía la población y la necesidad de crear nuevas fuentes de ingresos. En este nuevo contexto, los excedentes podían convertirse en capital inicial para nuevas actividades. Destinarlo a obtener prestigio dentro de la comunidad mediante la asunción de cargos festivos ya no tenía el interés de antaño.

Otro elemento que favoreció la crisis del sistema de fiestas fue la consolidación de la estructura burocrática del Estado. Tiempo atrás, asumir cargos festivos era un proceso necesario para alcanzar cargos políticos comunitarios de relevancia. Sin embargo, a medida que la estructura estatal se fue haciendo más patente, los cargos políticos tradicionales (varayoc) perdieron poder frente a otros nuevos de carácter estatal (gobernador, alcalde). El interés de los amantaneños económicamente preponderantes por asumir cargos políticos no solo se debía a una cuestión de prestigio, sino también a que ello les permitía controlar recursos públicos. En la medida que alcanzar estos cargos políticos ya no dependía de haber asumido previamente cargos festivos, disminuyó el interés por arrogárselos.

No obstante, la tradición y la presión de sus paisanos les obligaba a ello. En estas circunstancias, la conversión religiosa apareció como una estrategia que podía permitir liberarse de esas obligaciones ceremoniales. El adventismo, como la mayoría de las religiones protestantes o pentecostalistas que se han difundido por el área andina, considera pernicioso todo gasto que no se destine a la creación de riqueza, especialmente si va acompañado del consumo de productos prohibidos como el alcohol o la coca (Salas, 2018). Estos principios coincidían con los intereses de aquellos amantaneños deseosos de inhibirse de las obligaciones tradicionales para destinar sus excedentes a actividades económicas propiciadas por el mercado capitalista. Es así que durante las décadas del setenta y ochenta un grupo de isleños de nivel económico medio y alto se mostró propenso al cambio religioso. Eran campesinos que decidieron invertir sus excedentes en la adquisición de embarcaciones a motor para hacerse transportistas. Era una apuesta costosa, tanto por el capital inicial necesario en el momento de adquirir la lancha como por su mantenimiento posterior. Para estos amantaneños era crucial inhibirse de los gastos ceremoniales tradicionales. Solo así podían acumular el capital necesario para convertirse en transportistas. La IASD les ofreció la posibilidad.

La Tabla 2 nos descubre que un porcentaje importante de los lancheros que había en 1990 eran adventistas o lo habían sido en algún momento de la década anterior. En la década del ochenta, 
cuando, según datos ofrecidos oralmente por la Misión del Lago Titicaca de la IASD, el número de adventistas en Amantaní era de 335, es decir, el porcentaje de amantaneños adventistas era del $8,5 \%$. Sin embargo, más de la mitad de los lancheros eran adventistas.

Tabla 2. Lancheros adventistas por lanchas en 1985 y 1995.

\begin{tabular}{|c|c|c|c|c|}
\hline $\begin{array}{l}\text { Nombre } \\
\text { de la embarcación }\end{array}$ & $\begin{array}{c}\text { No } \\
\text { de lancheros } \\
\text { en } 1985\end{array}$ & $\begin{array}{c}\text { Lancheros } \\
\text { adventistas en } \\
1985\end{array}$ & $\begin{array}{c}\mathrm{No}^{\circ} \\
\text { de lancheros } \\
\text { en } 1995\end{array}$ & $\begin{array}{c}\text { Lancheros } \\
\text { adventistas en } \\
1995\end{array}$ \\
\hline Arca de Noé & 5 & 3 & 5 & 3 \\
\hline Inca & 7 & 2 & 7 & 1 \\
\hline Halcón & 6 & 4 & 6 & 2 \\
\hline Tarzán & 9 & 7 & 9 & 5 \\
\hline Atún & 6 & 4 & 5 & 2 \\
\hline Picaflor & 5 & 0 & 5 & 0 \\
\hline Independencia & 10 & 5 & 10 & 2 \\
\hline $\mathrm{La} \mathrm{Paz}$ & 9 & 4 & 9 & 2 \\
\hline 8 de Diciembre & & & 5 & 1 \\
\hline Sol y Mar & & & 7 & 3 \\
\hline Solimar & & & 4 & 0 \\
\hline Rey Marino & & & 4 & 0 \\
\hline Pilcomayo & & & 5 & 0 \\
\hline Estrella & & & 5 & 5 \\
\hline Virgen de la C. & & & 1 & 0 \\
\hline TOTAL & 57 & 29 & 87 & 26 \\
\hline PORCENTAJE & & $50,90 \%$ & & $29,90 \%$ \\
\hline
\end{tabular}

Fuentes: Libro de Actas del Sargento de Playa de Amantani, Libro de Actas de la Empresa de Transporte Turistica Lacustre, y entrevistas de campo.

La Tabla 2 también evidencia que la conversión religiosa entre los lancheros no había sido generalizada. Varios factores actuaron para que así fuera. Por un lado, ser adventista conlleva una serie de sacrificios que no todos estaban dispuestos a realizar. Entre ellos, prohibiciones alimentarias (alcohol, coca, carne porcina y de cuy), y tener que ceder a la IASD una parte de las ganancias (diezmo). Pero posiblemente la razón más significativa fue que no era necesaria la conversión de todos. Que una parte sustancial de los amantaneńos considerados ricos fuesen adventistas sirvió de ejemplo y excusa al resto, lancheros o no, para eximirse de sus obligaciones ceremoniales.

A modo de ejemplo podemos observar la evolución de la fiesta más importante de la comunidad: San Sebastián, que se celebra el segundo jueves del año. Tradicionalmente los propietarios de embarcaciones eran los encargados de cubrir parte de los gastos de esta festividad. 
Pero durante la segunda mitad de los setenta, los lancheros se descargaron de esa responsabilidad, aduciendo que los gastos podían y debían ser asumidos por la comunidad y con los alimentos donados por Cáritas. En los noventa los gastos de la festividad eran sufragados por todos los isleńos mediante cuota.

Las fiestas privadas también vieron reducidos sus fastos. Antaño los festejos de boda duraban tres días. A mediados de la década del noventa, normalmente duraban un solo día, en pocos casos dos. Quienes iniciaron esta práctica fueron los adventistas. En la dialéctica entre dejar de celebrar este tipo de fiestas, como su ética religiosa demanda, y mantenerlas, como propugna la tradición, optaron por una postura intermedia: reducir su duración y dispendio. Esta práctica fue rápidamente emulada por el resto de la comunidad.

\section{Cambio de estrategias y alianzas: caducidad del adventismo para los intereses lancheros}

Entre 1982 y 1990 no se formó ninguna nueva sociedad lanchera en Amantaní. Sin embargo, entre 1991 y 1995 surgieron siete, lo que prácticamente dobló el número de embarcaciones existentes. Y la mayor parte de estas nuevas sociedades (cinco) se establecieron entre 1994 y 1995 (Tabla 2).

Un factor que explica este fenómeno fue el impulso que vivió el turismo en el Perú tras la desarticulación de las guerrillas de Sendero Luminoso y del Movimiento Revolucionario Túcac Amaru, MRTA. Las perspectivas, que se evidenciaron ciertas, de un incremento del turismo en Amantaní animaron a muchos isleños a invertir en nuevas cooperativas lancheras. Otro fue la aceptación de que no se establecería ningún mecanismo de distribución del alojamiento turístico. El turismo seguía siendo considerado un recurso de propiedad comunal: todos los isleńos tenían derecho a su acceso. Pero era evidente que para activar ese derecho era necesario poseer la herramienta que lo "produce": la lancha. Amantaneńos que habían sido críticos con los patrones y reclamaban un sistema de reparto equitativo de los turistas cambiaron de estrategia: cinco de las siete nuevas sociedades formadas entre 1991 y 1995 estaban compuestas por reconocidos detractores del monopolio lanchero.

Las estrategias y alianzas permutaron a la par que cambió el contexto. Por ejemplo, los nuevos lancheros establecieron alianzas con los antiguos. El incremento del número de lanchas no supuso una reducción de los ingresos por embarcación, pues se dio paralelamente al aumento del número de visitantes. De hecho, el ritmo de incremento de lanchas fue inferior al del turismo.

El nuevo contexto también comportó un cambio en la estrategia religiosa. Como se observa en la Tabla 2, el porcentaje de patrones adventistas se redujo notablemente durante la primera mitad de la década del noventa. En parte, porque muchos lancheros antiguos abandonaron la IASD. También, porque en general los nuevos no eran, ni nunca fueron, adventistas. De los 31 lancheros de las siete sociedades formadas entre 1991 y 1995, solo nueve profesaban esa fe. $\mathrm{Si}$ tenemos en cuenta que varias de las nuevas sociedades lancheras surgieron de escisiones de otras más antiguas, el número de patrones advenedizos no-adventistas resulta mayor.

Este fenómeno se explica por la rigidez de los principios adventistas. Además, muchos asumieron como gobernadores, un cargo que obliga a promover y participar activamente en fiestas y a convidar y tomar bebidas alcohólicas. Por esta razón, temerosos de las críticas que pudieran 
recibir de sus "hermanos en la fe", la mayoría dejaba de acudir temporalmente al Templo; un alejamiento que muchas veces se convertía en permanente.

Pero la principal razón radicaba en que la función que había tenido el adventismo para los lancheros, como estrategia para eximirse de ciertos gastos ceremoniales, estaba desapareciendo. Como ya hemos explicado, el sistema de fiestas basado en cargos religiosos, y los mecanismos de redistribución de excedentes que lo acompañaba, ya estaba desarticulado en la década del noventa. Si bien aún se mantenía una fiesta de estas características, la resistencia a asumir el cargo ya no suponía una transgresión social. Incluso los católicos habían adoptado prácticas iniciadas por los adventistas dirigidas a disminuir los costos de las festividades particulares. En esta década los amantaneños no solo dependían económicamente del mercado capitalista, sino que estaban articulados a él ideológicamente. Sin duda, el adventismo encauzó este proceso, pero su función ya no era necesaria. Ahora era posible sustraerse de obligaciones ceremoniales tradicionales sin caer en el ostracismo.

En estas circunstancias, el adventismo se volvió una carga pesada. Un caso paradigmático es el de Alfredo V.C. A mediados de los noventa, Alfredo era uno de los principales líderes lancheros, había sido gobernador durante dos años, y en buena medida seguía controlando esta institución como personero en Amantaní de Cambio-90, el partido oficialista durante el régimen de Alberto Fujimori. En la década del ochenta también se había convertido en uno de los dirigentes adventistas, y como tal era uno de los fieles más estrictos en el cumplimiento de los preceptos religiosos. Pero en 1995, abandonó la IASD.

Los cargos políticos, sea cual sea su confesión, no pueden excusarse de participar en una serie de eventos que se contraponen con los principios adventistas: deben ir a la iglesia (católica) los domingos, apoyar las fiestas y participar en ellas, tomar alcohol para granjearse o mantener el respeto de sus conciudadanos, etcétera. Durante los dos ańos que Alfredo fue gobernador intentó eximirse de estas imposiciones, pero tampoco se negó a ellas cuando consideraba que estaba en juego su autoridad. Esto le supuso ser objeto de críticas dentro de la comunidad adventista. Alfredo no abandonó la IASD durante su período como gobernador, pero sus objetivos políticos posteriores le obligaron a llevar un doble juego. Por una parte, pretendía mantener el apoyo que recibía de sus "hermanos en la fe". Pero por otra, su deseo de conseguir el cargo de alcalde, al que se presentó en todas las elecciones municipales tras su período como gobernador, le obligaba a participar en las festividades y a convidar a sus vecinos a "tomar" (beber alcohol). Era una continua campańa destinada a obtener las simpatías de los no-lancheros católicos. En los cálculos de Alfredo, obtener parte de ese voto era esencial para el éxito de su candidatura. En esta coyuntura, los preceptos adventistas se habían vuelto un lastre para sus intereses políticos. Las críticas de sus "hermanos" a su comportamiento aumentaban. Llegó un momento en que no pudo sostener esta dualidad. Finalmente, Alfredo decidió dejar de ser adventista. Al fin y al cabo, esta nueva estrategia no dańaba sus intereses económicos: ya había pasado por el cargo de gobernador y, como hemos explicado, la función del adventismo como excusa para inhibirse de obligaciones ceremoniales estaba en crisis. Cabe destacar que la movilidad entre religiones es una práctica nada inusual en el área andina (Paerregaard, 1994). El interés de Alfredo en continuar dentro de la IASD estaba en el apoyo político que podía recibir de sus "hermanos en la fe". Pero mantener este apoyo suponía perder la posibilidad de ganar el del otro sector de isleños, más numeroso. En el año 2003, ya como católico, consiguió ser alcalde. Finalizada su etapa política, ya no regresó al Templo. No obstante, aseguraba intentar seguir los principios y preceptos adventistas, que consideraba los más sensatos. 


\section{Conclusiones}

Cuando el sistema de haciendas entró en crisis, la reacción indígena fue conservadora. Los levantamientos campesinos tenían como objetivo reclamar el mantenimiento de la economía moral que regía las relaciones de producción. Estas relaciones les aseguraban su reproducción, a la vez que legitimaban el papel del hacendado como administrador de poblaciones. Pero cuando vieron que la crisis era irreversible, las posteriores estrategias fueron diametralmente opuestas. Entonces reclamarán dejar de ser indígenas tutelados para convertirse en ciudadanos de pleno derecho. El cambio religioso será un medio para conseguirlo. Con la conversión a la fe adventista buscaban acceder a la escolarización y a la alfabetización, y de esta manera convertirse en sujetos políticos y ciudadanos de pleno derecho, y hacer más eficiente sus reclamaciones económicas frente a la hacienda.

La conversión religiosa también jugó un papel en las transformaciones que vivió la isla en las últimas décadas del mismo siglo. La adscripción a la IASD fue la vía que utilizaron aquellos sectores mejor situados económicamente para, por un lado, eximirse de las obligaciones tradicionales de redistribución de sus excedentes a través del sistema de cargos; y por otro, para controlar las instituciones políticas y, de esta manera, destinar recursos comunitarios a sus intereses de grupo y legitimar su monopolio del recurso turístico.

Así pues, la relación entre modernización y conversión religiosa parece clara en el caso amantaneño. ${ }^{7}$ Es una relación ya detectada por numerosos investigadores en la estela abierta por Max Weber (p.e., Sexton, 1978; Mitchell, 1991; Berger, 2010). El dilema está en descubrir la naturaleza de esta relación. El elemento que hace pensar en el carácter estratégico del cambio religioso es que la IASD no cambió su doctrina a lo largo del siglo pasado. Sin embargo, en Amantaní fue primero un instrumento en manos de los indígenas en su enfrentamiento contra un sistema de hacienda anquilosado y en crisis. Y posteriormente, unas décadas después, fue el sector hegemónico el que la utilizó para desligarse de obligaciones tradicionales y destinar sus recursos a las nuevas posibilidades que ofrecía la economía global. En diferentes momentos, y a grupos situados en distinto nivel de la escala social, el adventismo ofreció instrumentos y cobertura ideológica para la modernización. Sectores indígenas activaron sus preceptos pragmática y estratégicamente cuando coincidieron con sus objetivos políticos e intereses económicos.

¿Pero la conversión religiosa es una maniobra planificada? Autores que también han detectado el uso estratégico del cambio religioso parecen considerar que sí, especialmente en relación al papel que las nuevas religiones están jugando en las últimas décadas en el campo de la política institucional (Smilde, 2003). Es una aproximación a la denominada Rational Choice Theory of Religion (Young, 1996), que tuvo cierto predicamento en la década del noventa, y luego fue ampliamente contestada (Spickard, 1998). En Amantaní, la población no parece consciente de la relación entre sus intereses y su práctica religiosa. Ni siquiera los isleños, que en las décadas del ochenta y noventa criticaban el monopolio del turismo por parte de los lancheros, eran capaces de explicar por qué tantos eran adventistas. Lo atribuían a la casualidad o a que unos convencían a otros gracias a su estrecha relación laboral. La teoría constructivista de Bourdieu (1979, 1980) permite explicar esta aparente paradoja. Para el sociólogo francés, el individuo

7 Hablamos de "modernización" en el sentido que le da Habermas (1985) para distinguirlo del concepto "modernidad". Modernización hace referencia a la capitalización de los recursos, al desarrollo de las fuerzas productivas y al surgimiento de formas de vida urbana. Se sitúa, así, en el ámbito de lo socioeconómico. 
es capaz de orientar su conducta de forma coherente y ajustada hacia un objetivo, sin que sea producto de un cálculo razonado o lo haga consciente de la finalidad. El principio generador de este fenómeno se encuentra en el concepto habitus.

Dos elementos que caracterizan el habitus interesan para el caso que nos ocupa. El primero es que esta conducta, inconsciente y racional a la vez, y que rige buena parte de la vida cotidiana, es producto de la historia, del ambiente familiar y de la clase social a la que pertenece el individuo, sin que por ello se trate de un elemento estático. El habitus es capaz de ajustarse a nuevas situaciones y de crear nuevas prácticas. Es decir, admite el cambio. La conversión religiosa es una innovación que rompe con preceptos sociales y culturales previos. Pero una innovación que permite adecuar el habitus a un contexto cambiante.

El segundo elemento es que el habitus impide que el individuo analice objetivamente la realidad social. Por el contrario, le da una percepción que depende de formas simbólicas institucionalizadas. Esto dificulta que el adepto interprete su fe como una estrategia de clase. La conversión se basa en la creencia, por parte del neófito, de que la práctica y doctrina propugnadas por la nueva religión son las adecuadas, sin advertir la coincidencia con sus intereses de grupo y con las prácticas económicas y sociales que le son más beneficiosas.

Considerar el carácter estratégico de la conversión religiosa en Amantaní no niega que los creyentes no incorporen prácticas y principios morales fomentados por los preceptos adventistas. Los isleños adventistas son identificados como pulcros en su higiene personal y en el vestir, han abandonado el consumo de carne de cuy, nunca o raramente beben alcohol, no mascan coca, se relacionan con Dios y no con santos o la Virgen, y parecen más interesados en la educación de sus hijos. Son actitudes y creencias que van más allá de aquellas útiles a sus intereses sociales, políticos o económicos, y que se mantienen incluso cuando el individuo abandona el adventismo. Y es que, como afirma Cox (1995), el éxito de una religión solo es posible si ofrece elementos para enfrentar los desafíos de la vida, pero también ha de ser capaz de transformar la cosmovisión de los creyentes.

Por tanto, en el caso amantaneño, la religión no solo es un conjunto de creencias o un sistema que permite dar coherencia a un grupo social, como afirman las teorías funcionalistas, sino también un campo en el que se ponen en juego estrategias socioeconómicas (Worsley, 1968) y en el que se expresa la racionalidad reproductiva (Iturra, 1991), conscientemente o no. Estrategias que cambian dependiendo de las transformaciones del contexto y de los intereses individuales y de grupo.

\section{Agradecimientos}

El presente trabajo forma parte de una investigación más amplia que ha sido posible gracias al apoyo del proyecto "Turismo de base local y resiliencia socio-ecológica", otorgado por el Ministerio de Economía, Industria y Competitividad del Estado español (Ref. CSO201784893-P). 


\section{Referencias citadas}

Andrade, S. (2015). Protestantismo indigena: Procesos de conversión religiosa en la provincia de Chimborazo, Ecuador. Quito: FLACSO - IFEA.

Annis, S. (1987). God and production in a Guatemalan town. Austin, TX: University of Texas Press.

Armas Asín, F. (2002). Libertad religiosa, violencia y derechos humanos en el Perú de fines del siglo XX. En Marzal, M. (Ed.). La religión en el Perú al filo del milenio (109-137). Lima: PUCP.

Basadre, J. (1980). Elecciones y centralismo en el Perú: Apuntes para un esquema histórico. Lima: Universidad del Pacífico.

Bastian, J.-P. (1983). Protestantismo y Sociedad en México. México: CUPSA.

Berger, P.L. (2010). Max Weber is alive and well, and living in Guatemala: The Protestant ethic today. The Review of Faith \& International Affairs, 8(4), 3-9. doi:10.1080/15570274.2010.528964

Bourdieu, P. (1979). La Distinction: Critique sociale du jugement. Paris: Les Éditions de Minuit.

Bourdieu, P. (1980). Le sens pratique. Paris: Les Éditions de Minuit.

Burga, M. y Flores Galindo, A. (1984). Feudalismo andino y movimientos sociales (1866 1965). En Historia del Perú: Procesos e Instituciones. Tomo XI. Lima: Juan Mejía Baca.

Caram Padilla, M. J. (1997). Identidades creyentes en tiempos de cambio: Católicos y adventistas aimaras del distrito de Pilcuyo, Puno. Allpanchis, 50, 9-68.

Carlsen, L. (1999). Autonomía indígena y usos y costumbres: la innovación de la tradición. Revista Chiapas, 7, 45-70. Recuperado de https://chiapas.iiec.unam.mx/No7-PDF/ch7carlsen.pdf

Carrasco, Pedro (1983). La autonomía relativa del campo religioso rural. Cristianismo y Sociedad, 76, 35-40.

Carter, W. E. (1965). Innovation and marginality: Two South American case studies. América Indigena, 25(4), 383-392.

Cleary, E. L. y Steigenga, T. J. (Eds.). (2004) Resurgent voices in Latin America: Indigenous peoples, political mobilization, and religious change. Piscataway, NJ: Rutgers University Press.

Cox, H. (1995). Retour de Dieu: Voyage en pays pentecôtiste. Paris: Descleé de Brouvner.

Crain, M. M. (1989). Ritual, memoria popular y proceso politico en la sierra ecuatoriana. Quito: Abya-Yala.

De la Torre, R. (2014). El estudio de la religión en México enmarcado en el campo intelectual y el campo del poder. Sociedad y Religión, 24(42), 67-91. Recuperado de: https://www.redalyc.org/ pdf/3872/387239045004.pdf

Diamond, S. (1989). Spiritual Warfare: The Politics of the Christian Right. Boston, MA: South End Press.

Discurso del alcalde de Capachica (23 de agosto de 1952). Los Andes, p. 8. Puno.

Flores Galindo, A. (1977). Arequipa y el Sur Andino: Siglos XVII-XX. Lima: Horizonte.

Foster, G. M. (1972[1967]). Tzintzuntzan. México: FCE. 
Gascón, J. (1999). El control y explotación de la mano de obra colona en la hacienda andina peruana. Anuario de Estudios Americanos, 56(1), 195-215. doi:10.3989/aeamer.1999.v56.i1.293

Gascón, J. (2000). Sublevaciones colonas y reproducción del sistema de haciendas en el Sur Andino Peruano. Revista Española de Antropología Americana, 30, 265-289.

Gascón, J. (2005a). Compadrazgo y Cambio en el Altiplano Peruano. Revista Española de Antropología Americana, 35, 191-206.

Gascón, J. (2005b). Gringos como en sueños: Diferenciación y conflicto campesino en los Andes Peruanos ante el desarrollo del turismo. Lima: IEP.

Gascón, J. (2011). Turismo rural comunitario y diferenciación campesina: Consideraciones a partir de un caso andino. Mundo Agrario, 11(22). Recuperado de: https:/www.mundoagrario.unlp.edu.ar/article/ view/v11n22a01

Gascón, J. (2015). Turismo comunitario y vinculación religiosa en los Andes centrales. Revista Andaluza de Antropología, 8, 68-89. doi:10.12795/RAA.2015.i08.04

Gascón, J. (2017). Acabando con la administración de poblaciones: Razones y estrategias para reclamar la plena ciudadanía en la hacienda surandina peruana. En Bretón, V. y Vilalta, M. J. (Eds.). Poderes y personas (pp. 195-216). Barcelona: Icaria.

Gill, L. (1990). "Like a veil to cover them": Women and the Pentecostal movement in La Paz. American Ethnologist, 17(4), 708-721. doi:10.1525/ae.1990.17.4.02a00060

González Prada, M. (1981 [1904]). Nuestro indios. En Horas de lucha (177-190). Lima: Universo.

Guerrero, A. (2010). Administración de poblaciones, ventriloquia y transescritura. Quito / Lima: FLACSO - IEP.

Habermas, J. (1985). Le discours philosophique de la modernité. Paris: Gallimard.

Hvalkof, S. y Aaby, P. (1981). Is God an American? An anthropological perspective on the missionary work of the Summer Institute of Linguistics. Copenhagen / London: Iwgia \& Survival International.

Iturra, R. (1991). Factores de reproducción social en sistema rurales: Trabajo, producción de productores y pecado en aldeas campesinas. En Prat, L. et al. (Eds.). Antropología de los Pueblos de España (pp. 485-497). Madrid: Taurus.

Lalive d'Epinay, C. (1968). El refugio de las masas: Estudio sociológico del protestantismo chileno. Santiago: Pacífico.

López Jiménez, S. (2010). Estado y ciudadanía en el Perú. En Adrianzén, A. et al. (Eds.). El Estado en debate: Múltiples miradas (pp. 33-78). Lima: PNUD.

Mansilla, M. A., Leiva, S. y Piñones, C. (2020). Pentecostalismo de frontera y pentecostalismo de centro: Procesos de fronterización simbólica en el pentecostalismo altiplánico chileno-boliviano, 1973-2007. Estudios atacameños. Arqueología y Antropología Surandinas, 64, 297-318. doi:10.22199/issn.0718-10432020-0015

Mansilla, M. A., Muñoz, W. y Orellana, L. (2014). Los dilemas comunitarios y étnicos y religiosos: Las investigaciones antropológicas del pentecostalismo Aymara y Mapuche en Chile (1967-2012). Estudios atacameños. Arqueología y Antropología Surandinas, 49, 153-175. doi: 10.4067/S0718-10432014000300009 
Mariátegui, J. C. (1975 [1928]). Prólogo. En Valcárcel, L. E. Tempestad en los Andes (pp. 9-15). Lima: Universo.

Martin, D. (1989). Tongues of fire: The explosion of Protestantism in Latin America. Cambridge: Basil Clackwell.

Marzal, M. (1971). El mundo religioso de Urcos. Cusco: IPA.

Meillassoux, C. (1979). Historical modalities of the exploitation and over-exploitation of labour. Critique of Anthropology, 4(13/14), 7-16. doi:10.1177/0308275X7900401302

Miller, E. S. (1970). The Christian missionary agent of secularization. Anthropological Quartelly, 53(1), 1422. doi: $10.2307 / 3316563$

Miller, E. S. (1975). Shamans, power symbols, and change in Argentine Toba culture. American Ethnologist, 2(3), 477-496. doi:10.1525/ae.1975.2.3.02a00080

Mitchell, W. P. (1991). Peasants on the Edge: Crop, Cult and Crisis in the Andes. Austin: University of Texas Press.

Mücke, U. (2004). Elecciones y participación política en el Perú del siglo XIX: La campaña presidencial de 1871-72. Investigaciones sociales, 12, 133-169. doi:10.15381/is.v8i12.6887

Muratorio, B. (1982). Etnicidad, evangelización y protesta en Ecuador. Quito: CIESE.

Paerregaard, K. (1994). Conversion, migration, and social identity: The spread of Protestantism in the Peruvian Andes. Ethnos, 59(3/4), 168-186. doi:10.1080/00141844.1994.9981498

Peloso, V. C. (1996). Liberals, electoral reform and the popular vote in mid-nineteenth-century Peru. En Peloso, V. C. y Tenenbaun, B. (Eds.). Liberals, Politics and Power (pp. 186-211). London: University of Georgia Press.

Pérez, E. y Gascón, J. (1997). El impacto del turismo y de los proyectos de desarrollo de ONG's en la estructura social y económica de dos comunidades andinas. Agricultura y Sociedad, 84, 225-252.

Portocarrero, G. (1995). El fundamento invisible: Función y lugar de las ideas racistas en la República Aristocrática. En Panfichi, A. y Portocarrero, F. (Eds.). Mundos interiores: Lima 1850-1950 (pp. 219-260). Lima: Universidad del Pacífico.

Reina, R. E. y Schwartz, N. B. (1974). The structural context of religious conversion in Petén, Guatemala: Status, community, and multicommunity. American Ethnologist, 1(1), 157-191. doi:10.1525/ ae.1974.1.1.02a00090

Rodríguez, E. (1982). Un evangelio según la clase dominante. México: UNAM.

Salas, G. (2018). Evangelicalism in the Rural Andes. En Seligmann, L. J. y Fine-Dare, K. S. (Eds.). The Andean World (pp. 280-296). New York, NY: Routledge.

Sexton, J. D. (1978). Protestantism and modernization in two Guatemalan towns. American Ethnologist, 5(2), 280-302. doi:10.1525/ae.1978.5.2.02a00060

Smilde, D. (2003). Skirting the Instrumental Paradox: Intentional Belief Through Narrative in Latin American Pentecostalism. Qualitative Sociology, 26(3), 313-329. doi:10.1023/A:1024014225750 
Spickard, J. V. (1998). Rethinking religious social action: What is "rational" about rational-choice theory? Sociology of Religion, 59(2), 99-115. doi:10.2307/3712075

Stoll, D. (1990). Is Latin American Turning Protestant?: The Politics of Evangelical Growth. Berkeley \& Los Angeles, CA: University of California Press.

Ströbele-Gregor, J. (1989). Indios de piel blanca: Evangelistas fundamentalistas en Chuquiyawu. La Paz: HISBOL.

Teel, C. (1989). Las raíces radicales del adventismo en el Altiplano peruano. Allpanchis, 33, 209-248.

Teel, C. (2009). Histórias missionárias e o futuro do adventismo: Fernando e Ana Stahl como um estudo de caso. A Revista Formadores: Vivências e Estudos, 2(3), 467-477.

Willems, E. (1967). Followers of the New Faith: Culture Change and the Rise of Protestantism in Brazil and Chile. Nashville, TN: Vanderbilt University.

Worsley, P. (1968[1957]). The Trump shall sound: A study of Cargo Cults in Melanesia. New York, NY: Schocken Books.

Young, L. (1996). Rational Choice Theory and Religion: Summary and Assessment. New York, NY: Routledge. 